\title{
Autonomy Support of Nursing Home Residents With Dementia in Staff-Resident Interactions
}

Citation for published version (APA):

Hoek, L. J. M., Verbeek, H., de Vries, E., van Haastregt, J. C. M., Backhaus, R., \& Hamers, J. P. H. (2020). Autonomy Support of Nursing Home Residents With Dementia in Staff-Resident Interactions: Observations of Care. Journal of the American Medical Directors Association, 21(11), 1600-1608. https://doi.org/10.1016/j.jamda.2020.04.013

Document status and date:

Published: 01/11/2020

DOI:

10.1016/j.jamda.2020.04.013

Document Version:

Publisher's PDF, also known as Version of record

Document license:

Taverne

Please check the document version of this publication:

- A submitted manuscript is the version of the article upon submission and before peer-review. There can be important differences between the submitted version and the official published version of record.

People interested in the research are advised to contact the author for the final version of the publication, or visit the DOI to the publisher's website.

- The final author version and the galley proof are versions of the publication after peer review.

- The final published version features the final layout of the paper including the volume, issue and page numbers.

Link to publication

\footnotetext{
General rights rights.

- You may freely distribute the URL identifying the publication in the public portal. please follow below link for the End User Agreement:

www.umlib.nl/taverne-license

Take down policy

If you believe that this document breaches copyright please contact us at:

repository@maastrichtuniversity.nl

providing details and we will investigate your claim.
}

Copyright and moral rights for the publications made accessible in the public portal are retained by the authors and/or other copyright owners and it is a condition of accessing publications that users recognise and abide by the legal requirements associated with these

- Users may download and print one copy of any publication from the public portal for the purpose of private study or research.

- You may not further distribute the material or use it for any profit-making activity or commercial gain

If the publication is distributed under the terms of Article $25 \mathrm{fa}$ of the Dutch Copyright Act, indicated by the "Taverne" license above, 
Original Study

\title{
Autonomy Support of Nursing Home Residents With Dementia in Staff-Resident Interactions: Observations of Care
}

\author{
Linda J.M. Hoek MSc, Hilde Verbeek PhD*, Erica de Vries MSc, \\ Jolanda C.M. van Haastregt PhD, Ramona Backhaus PhD, Jan P.H. Hamers PhD \\ Department of Health Services Research, Care and Public Health Research Institute (CAPHRI), Maastricht University, Maastricht, The Netherlands
}

Keywords:

Nursing home

dementia

autonomy

observation

nursing staff

\begin{abstract}
A B S T R A C T
Objectives: People with dementia living in nursing homes benefit from a social environment that fully supports their autonomy. Yet, it is unknown to what extent this is supported in daily practice. This study aimed to explore to which extent autonomy is supported within staff-resident interactions.

Design: An exploratory, cross-sectional study.

Setting and Participants: In total, interactions between 57 nursing home residents with dementia and staff from 9 different psychogeriatric wards in the Netherlands were observed.

Methods: Structured observations were carried out to assess the support of resident autonomy within staff-resident interactions. Observations were performed during morning care and consisted of 4 main categories: getting up, physical care, physical appearance, and breakfast. For each morning care activity, the observers consecutively scored who initiated the care activity, how staff facilitated autonomy, how residents responded to staff, and how staff reacted to residents' responses. Each resident was observed during 3 different mornings. In addition, qualitative field notes were taken to include environment and ambience.

Results: In total, 1770 care interactions were observed. Results show that autonomy seemed to be supported by staff in $60 \%$ of the interactions. However, missed opportunities to engage residents in choice were frequently observed. These mainly seem to occur during interactions in which staff members took over tasks and seemed insensitive to residents' needs and wishes. Differences between staff approach, working procedures, and physical environment were observed across nursing home locations.

Conclusions and Implications: The findings of this study indicate that staff members support resident autonomy in more than one-half of the cases during care interactions. Nonetheless, improvements are needed to support resident autonomy. Staff should be encouraged to share and increase knowledge in dementia care to better address residents' individual needs. Especially for residents with severe dementia, it seems important that staff develop skills to support their autonomy.
\end{abstract}

(c) 2020 AMDA - The Society for Post-Acute and Long-Term Care Medicine.
This work was supported by the Living Lab in Aging and Long-Term Care. They had no role in the design and conduct of the study; in the collection, analysis, and interpretation of data; in the preparation of the manuscript; or in the review or approval of the manuscript. The research was funded by the seven long-term care organizations Meandergroep Zuid-Limburg, Sevagram, Envida, Cicero Zorggroep, Zuyderland, Vivantes, MosaeGroep, and the Maastricht University, within the Living Lab in Ageing and Long-Term Care.

The authors declare no conflicts of interest.

* Address correspondence to Hilde Verbeek, PhD, Maastricht University, Faculty of Health, Medicine and Life Sciences, CAPHRI Care and Public Health Research Institute, Department of Health Services Research, PO Box 616, 6200 MD Maastricht, The Netherlands.

E-mail address: h.verbeek@maastrichtuniversity.nl (H. Verbeek).
In the past 2 decades, efforts have been made to provide personcentered care that is more responsive to nursing home residents' needs and wishes. ${ }^{1-3}$ Person-centered care focuses on addressing individual needs and maintaining selfhood within an interpersonal relationship. ${ }^{3}$ It underlines respecting, valuing, and understanding persons with dementia and their caregivers, through positive interactions and social events. ${ }^{4}$ Universal human needs of autonomy, relatedness, and competence are important aspects of well-being for people with dementia in nursing homes. ${ }^{4,5}$ Autonomy can be defined as one's ability to live the life one wants to live. Experiencing control and having freedom of choice are seen as expressions of autonomy. ${ }^{6,7}$ People with dementia often face difficulties voicing their needs and wishes, and they may need support from their social environment to express their autonomy. However, being dependent on others and 
receiving support does not decrease residents' need for autonomy. ${ }^{8,9}$ Therefore, concepts of relational autonomy and human interdependency should be considered in caregiving. ${ }^{10}$ Within social relationships, autonomy can either be facilitated or impeded, and residents can still exercise autonomy regardless of their level of dependence on others because of cognitive or physical impairments. Nonetheless, stimulating autonomy within care remains a challenge. ${ }^{11}$

Although the concept of person-centered care has received considerable attention during past decades, ${ }^{12}$ little is known about the extent to which resident autonomy is supported by staff in practice during daily care in nursing homes. Staff sensitivity to residents' needs for social interaction, providing genuine attention, and building a trusting relationship are important to increase the feeling of resident autonomy. ${ }^{13}$ In addition, staff need to engage residents in choice as much as possible. ${ }^{14,15}$ For example, staff can support choice by showing food choices to residents, or by asking closed-ended (yes/no) questions regarding wishes for daily activities. Nonetheless, research suggests that nursing home residents with dementia may not be adequately engaged in choice by their social environment. ${ }^{14,16}$ To support resident autonomy, it is essential to use adequate (non)verbal communication that is adapted to residents' understanding (eg, being alert to cues, recognizing individuality and personality, informing and discussing, understanding "beyond the spoken word," avoiding elderspeak, and controlling language). ${ }^{17-20}$

Previous studies suggest that exercising autonomy is often influenced by factors regarding how nursing home residents are approached by staff and by institutional factors. ${ }^{21-23}$ Although knowing the person is considered important in providing personcentered care, staff can limit resident autonomy by making decisions based on previous experiences or interpretation of resident preferences. $^{22,23}$ Consequently, they neglect assessing preferences and exclude residents from decision-making. ${ }^{24}$ In addition, as staff may stereotype residents as "old" and lacking physical and cognitive capacity to exercise autonomy, residents are not perceived as persons with individual preferences and are not taken seriously in decision-making. ${ }^{12,21,25}$ Therefore, care should focus beyond physical and cognitive impairments and seek possibilities to enable residents to live life as fully as possible. ${ }^{26}$ Nonetheless, the shift toward providing person-centered care remains challenging, as traditional working routines and processes focus on medical care within current nursing home practice. Most staff-resident interactions focus on finishing care tasks, regardless of the resident's needs and wishes. ${ }^{13,27}$ In addition, institutional factors such as routines, restricted door access, or having to live with strangers can also be barriers to resident autonomy. ${ }^{28-30}$

Knowledge of how autonomy is supported within staff-resident interactions is needed to increase knowledge of how to support resident autonomy in current practice. Important information on indicators of autonomy for nursing home residents has been provided. ${ }^{28-30}$ Nonetheless, research on the subject has mostly been restricted to autonomy as a subdomain within person-centered care, and primarily incorporates staff perception of whether or not they perceive that residents are empowered in decision-making, involved in care planning, or have control over care. ${ }^{31-34}$ Moreover, autonomy is often linked to practical matters (eg, whether or not residents can bring their own belongings, listen to music of their choice, spend time with animals, or eat when and where they want). More research is needed to incorporate the relational perspective on autonomy in order to cover more aspects of autonomy within daily nursing home care. Therefore, the aim of this study is to explore to which extent autonomy is supported within nursing homes for residents with dementia during staff-resident interactions. This is one of the first studies that explores how resident autonomy is supported within current practice by staff, and aims to describe patterns of how autonomy is supported within staff-resident interactions. In addition, a preliminary exploration of how the support of autonomy differs for residents with different cognitive and physical functioning within this sample was conducted.

\section{Methods}

\section{Study Design}

We conducted an exploratory, cross-sectional, observational study, in which qualitative and quantitative approaches are combined, between March 2017 and September 2018.

\section{Setting and Participants}

The sample consisted of people with dementia living in 9 different psychogeriatric wards of 6 nursing homes in the southern part of the Netherlands. Eligibility criteria required residents to have an official diagnosis of dementia, or a Standardized Mini-Mental State Examination (SMMSE) score lower than $24 .{ }^{35}$ A total of 120 residents met the inclusion criteria. To include a variety of perspectives from different nursing home environments, 5 large-scale wards and 4 small-scale wards from 5 different locations were included. In the Netherlands, 2 main types of nursing home facilities exist. ${ }^{36}$ Within the large-scale wards, care is provided for around 20 residents or more, and has a more traditional way of providing care. Within small-scale wards, the aim is to provide care within a homelike, personal environment for a small number of residents (approximately 6 to 8), where household activities are integrated into daily life. Staff members within the selected wards were included in the study if they provided morning care for the participating residents. In the Netherlands, the majority of nursing staff (88\%) consists of certified nursing assistants. Nurses who work in a nursing home in the Netherlands are required to have received education for at least 2 years. On average, staff had 15 years of nursing experience (with years ranging from 1 to 41 ) and $90 \%$ were certified nurses, $1.5 \%$ were registered nurses, and $8.5 \%$ support staff.

\section{Measures}

\section{Resident Characteristics}

A nurse provided information on residents' age, sex, and official dementia diagnosis. We measured cognitive status with the SMMSE with a score ranging from 0 to 30, with low scores indicating severe cognitive impairment. ${ }^{37}$ We assessed functioning on activities of daily living (ADL) with the Barthel index, with scores ranging from 0 to 20 and lower scores indicating a higher dependency in ADL functioning. ${ }^{38}$ We administered all characteristics within 3 weeks from the start of the observation period.

\section{The Support of Autonomy}

In this study, we observed the support of resident autonomy within staff-resident interactions during morning care, as staff-resident interactions occur frequently during this period. We clustered 11 morning care activities into 4 main categories: getting up, physical care, physical appearance, and breakfast (Table 1). Accordingly, as instruments to measure resident autonomy within staff-resident interactions are lacking, we developed a standardized observation list in several steps. First, we performed participant observations on weekdays to explore how we can observe the support of resident autonomy within practice. Next, we discussed these pilot observations and the developed observation list within the research team. Accordingly, a first version of the observation list was set, containing all morning care activities that could be observed, 
and a categorization of the steps occurring within staff-residentinteractions, such as "who took the initiative" or "how did the resident/staff member respond." We performed several test observations with the observation list to distinguish and define the definitions. We could have observed the care activities of toileting and medication, however, these were omitted from the observation list because of privacy issues and individual differences in medication use. This resulted in 11 morning care activities. Subsequently, we discussed the observation list within the research team to agree on step definitions and scoring. Finally, an observation guideline was developed and completed to standardize the observation method. Four trained observers (3 researchers and 1 research assistant) conducted the observations. All observers were trained by the first author. The first step was reading and discussing the protocol and guideline. Second, dual observations were conducted by the first author and 1 observer. These test observation consisted of approximately 3 mornings, observing all morning care activities for 6 residents per morning together. Scoring was evaluated afterward with the first researcher. After performing the first observations, we performed an evaluation to ensure alignment between the researchers Two observers (L.H., E.V.), who were involved in the majority of the observations, tested the observation reliability. They performed dual observations for 6 residents, and scored the complete observation list at the same time, for the same residents, to establish an absolute interobserver agreement. This was 93\%, based on calculating agreement scores for each scoring option of the observation list.

For each morning care activity, the observers consecutively selected an option within the following 4 categories (creating an "observation path"): (A) Initiative for care activity; (B) Facilitating autonomy; (C) Resident response to staff; and (D) Staff reaction to resident's approach, which is explained below (Detailed information is provided in Supplementary Material.)

(A) First step: Initiative for care activity (ie, who initiated the care activity? "resident" or "staff member.")

(B) Second step: Facilitating autonomy, ie, How did the nursing staff member approach the resident during the care activity? "Care activity without a verbal or nonverbal cue," "Care activity with verbal or nonverbal cues," or "Care activity with active support of choice."

(C) Third step: Resident response to staff approach, ie, how did the resident respond to the staff member's approach? "No reaction," "Positive reaction," or "Negative reaction."

(D) Fourth step: Staff reaction to resident's response, ie, how did the staff member react to the resident's response? "Staff member complies with the resident's request or reaction," "Staff member proposes an alternative, and resident agrees," "Staff member verbally responds to resident, but perseveres with own plan," or "Staff member ignores resident's reaction."

Field notes were taken during the observation period to describe the situation during all interactions and to document aspects that stood out regarding environment and ambience.

\section{Procedure}

The researcher observed each resident during all care activities on 3 randomly selected mornings (7:00-11:30 am on weekdays). We conducted continuous observations; all care activities were observed from beginning to end. For practical reasons, the researcher sometimes changed the observation order of care activities for 1 resident or rescheduled a part to the next day. Within each ward, a registered nurse assessed the background information for all participating residents by using residents' records, combined with their own knowledge about the residents. We scored
Table 1

Description of Care Activities

\begin{tabular}{|c|c|}
\hline Care Activities & Description \\
\hline $\begin{array}{l}\text { Getting up } \\
\text { Waking up } \\
\text { Getting out of bed }\end{array}$ & $\begin{array}{l}\text { The way in which a resident starts his/her day. It } \\
\text { entails the way a resident wakes up, gets out } \\
\text { of bed, and how his/her autonomy is } \\
\text { supported during both moments. }\end{array}$ \\
\hline $\begin{array}{l}\text { Physical care } \\
\text { Washing/bathing } \\
\text { Dental care }\end{array}$ & $\begin{array}{l}\text { The way in which a resident receives or } \\
\text { performs personal care. It entails how a } \\
\text { resident is approached and how personal } \\
\text { preferences are met regarding washing and } \\
\text { dental care. }\end{array}$ \\
\hline $\begin{array}{l}\text { Physical appearance } \\
\text { Clothing } \\
\text { Getting dressed } \\
\text { Hairdressing/grooming }\end{array}$ & $\begin{array}{l}\text { The way in which a resident wants to express or } \\
\text { present him or herself regarding physical } \\
\text { appearance. It entails how a resident is } \\
\text { approached and how personal preferences are } \\
\text { met regarding getting dressed, clothing, } \\
\text { hairdressing, or shaving. }\end{array}$ \\
\hline $\begin{array}{l}\text { Breakfast } \\
\text { Time to eat } \\
\text { What to eat } \\
\text { What to drink } \\
\text { Amount of breakfast }\end{array}$ & $\begin{array}{l}\text { The way in which breakfast is provided. It } \\
\text { entails how a resident is able to and wants to } \\
\text { have breakfast and how personal preferences } \\
\text { are met regarding time and type of breakfast. }\end{array}$ \\
\hline
\end{tabular}

observations on a small, printed, structured observation list. During the observation, the researcher took notes and completed the observation list.

\section{Ethical Considerations}

The Ethics Committee of Zuyderland-Zuyd approved this study (No. 16-N-233). Participants' family caregivers gave written informed consent after receiving information about the purpose and procedure of the study. During the observations, we assured informed assent from the residents (ie, the nurse asked each resident for their permission before the researcher entered the room). If residents gave permission, the researcher quietly sat down in the room. If the resident rejected the observer's presence, showed verbal or nonverbal negative mood signals, or when the resident was visibly distressed by the observer's presence, the observer would leave the room. ${ }^{39}$

\section{Data Analyses}

We digitalized and analyzed the observation lists, using the statistical software package SPSS v 25 (IBM SPSS Statistics for Windows, version 25 Armonk, NY). Descriptive statistics were used to obtain an overview of the distribution of who took the initiative for a care activity (step A), and how autonomy was facilitated by the staff member (step B). Next, to analyze complete observation paths (single interactions), steps A, B, C, and D were concatenated within the SPSS data file. We used frequency tables to obtain the proportion of each observation path within the sample. In addition, for the purpose of exploring how background characteristics (ie, SMMSE score and Barthel index score) related to different steps within the interactions and the observation paths, scores were categorized as follows. The SMMSE score was categorized into severe $(0-10)$, moderate (11-20), mild (21-26), and normal (27-30). ${ }^{36}$ The Barthel index score was categorized into low ADL dependency (15-20), ADL dependent/independent $(10-14)$, and high ADL dependency $(0-9) .{ }^{37}$ Next, the content of the field notes regarding environment and ambience within each location was used to describe the context across locations and nurses.

\section{Results}

Both quantitative and qualitative results are presented below. Sample proportions are followed by qualitative descriptions. 
Table 2

Resident Characteristics $(\mathrm{n}=57)$

\begin{tabular}{lc}
\hline Total & \\
\hline Mean age (SD; range) & $86.72(5.97 ; 61-97)$ \\
Female (\%) & $46(81)$ \\
Mean SMMSE score* (SD; range) & $9.40(7.58 ; 0-27)$ \\
SMMSE categorization (frequency; percentage) & \\
$\quad$ Severe (0-10) & $24(51.10)$ \\
Moderate (11-20) & $21(44.70)$ \\
Mild (21-26) & $1(2.10)$ \\
$\quad$ Normal (27-30) & $1(2.10)$ \\
Mean Barthel index score ${ }^{\dagger}(S D ;$ range) & $9.51(5.67 ; 0-20)$ \\
Barthel index score categorization & \\
$\quad$ (frequency; percentage) & $12(21.80)$ \\
Low dependency (15-20) & $20(36.40)$ \\
Dependent/independent (10-14) & $23(41.80)$ \\
High dependency (0-9) &
\end{tabular}

SD, standard deviation.

Underlined score indicates worse performance on scale.

*The SMMSE was assessed for 47 residents; 10 residents refused to participate, did not speak the language or were absent/sleeping multiple times during data collection.

†The Barthel index was assessed for 55 residents; we received no information on Barthel index scores from 2 residents.

\section{Sample Characteristics}

Of the 120 family caregivers of nursing home residents that we had approached for this study, 57 family caregivers gave informed consent (48\% of eligible residents within the selected nursing home wards). Table 2 presents their characteristics. On average, residents experienced moderate to severe loss of cognitive functioning and needed extensive assistance with regards to physical functioning. During the observation period, we observed 75 different staff members during interactions with the selected residents.

\section{Care Observations}

In total, we observed 1770 care interactions (Table 3). Because of residents passing away before or during the study period $(n=5)$, residents verbally refusing observation during an observation day $(\mathrm{n}=2)$, or residents who stayed in bed during the observation day or period, $94 \%$ of the intended observations $(n=1881)$ were completed.

\section{Initiative for Care Activity}

On average, staff initiated $72 \%$ of the care activities; whereas residents initiated an average of $20 \%$ of the activities (Table 3 ). Residents especially took initiative in "waking up" (69\%) and to a lesser degree in "getting out of bed" (35\%). Furthermore, dental care was frequently not performed during morning care observations (53\%).

Further exploration of the data indicates that residents with higher cognitive functioning (SMMSE) and higher independent ADL functioning (Barthel index) appeared to initiate care activities more often themselves. Residents with higher cognitive functioning initiated care activities in more than $82 \%$ of cases, whereas residents with low cognitive functioning initiated care activities in less than $19 \%$ of cases. Residents with higher independent ADL functioning initiated care activities in more than $40 \%$ of cases, whereas residents with lower independent ADL functioning initiated care activities in less than $8 \%$ of cases.

\section{Facilitating Autonomy}

In $30 \%$ of cases, staff performed the care activity without a verbal or nonverbal cue. An example of an observation is given below:

In a rush to get Mrs Peeters (all names are pseudonyms) ready for breakfast, nurse Ally gets a comb from the bathroom, walks up to Mrs Peeters, and starts brushing Mrs Peeters' hair really quick without saying anything-Observation hairdressing/grooming

In $39 \%$ of cases, staff performed the care activity with a verbal or nonverbal cue. An example is given below:

Nurse Mary picks up Mrs Jansen's dentures from the bathroom and shows them to Mrs Jansen, looks at her and jokingly says 'Let's get you some teeth'; Mrs Jansen laughs and opens her mouth-Observation dental care

In $31 \%$ of cases, staff actively supported resident autonomy by engaging them in choice. An example is given below:

The nurse softly knocks on the resident's door, enters the room and says, 'Good morning Mr Peeters,' as Mr Peeters had already put away the blanket; 'Do you want to get up already?' and Mr Peeters slowly nods-Observation getting up

Further descriptive analyses showed that residents with very low cognitive functioning (SMMSE score 0-10) seemed to more often be approached by the nurse without a cue during the care activities, in $32 \%$ of cases, than people with higher scores of cognitive functioning. Nurses seem to perform care activities without a verbal or nonverbal cue mostly for residents with low independent ADL functioning (59\% of cases). If the nurse performed the care activity without a cue, often residents showed no reaction (74\% of cases). If the nurse performed the care activity with a cue, or when the resident was engaged in

Table 3

Overview of Care Initiation

\begin{tabular}{|c|c|c|c|c|}
\hline \multirow[t]{2}{*}{ Care Activities (and Subcategories) } & \multirow[t]{2}{*}{ n (observed) } & \multicolumn{3}{|c|}{ Initiative } \\
\hline & & Staff & Resident & $\begin{array}{l}\text { Activity Not Performed } \\
\text { during Observation Period }\end{array}$ \\
\hline \multicolumn{5}{|l|}{ Getting up } \\
\hline Waking up & 165 & $31 \%$ & $69 \%$ & $0 \%$ \\
\hline Getting out of bed & 166 & $64 \%$ & $35 \%$ & $1 \%$ \\
\hline \multicolumn{5}{|l|}{ Physical care } \\
\hline Washing/bathing & 157 & $90 \%$ & $7 \%$ & $3 \%$ \\
\hline Dental care & 156 & $42 \%$ & $5 \%$ & $53 \%$ \\
\hline \multicolumn{5}{|l|}{ Physical appearance } \\
\hline Clothing & 167 & $81 \%$ & $16 \%$ & $3 \%$ \\
\hline Getting dressed & 167 & $84 \%$ & $13 \%$ & $3 \%$ \\
\hline Hairdressing/grooming & 164 & $76 \%$ & $16 \%$ & $8 \%$ \\
\hline \multicolumn{5}{|l|}{ Breakfast } \\
\hline Time to eat & 164 & $88 \%$ & $12 \%$ & $0 \%$ \\
\hline What to eat & 156 & $84 \%$ & $13 \%$ & $3 \%$ \\
\hline What to drink & 158 & $86 \%$ & $10 \%$ & $4 \%$ \\
\hline Amount of breakfast & 150 & $71 \%$ & $22 \%$ & $7 \%$ \\
\hline Total (mean) & 1770 & $72 \%$ & $20 \%$ & $8 \%$ \\
\hline
\end{tabular}


choice, the resident showed a (positive) reaction $(60 \%$ and $82 \%$ of cases, respectively).

\section{Variations in the Support of Autonomy}

In total, 21 variations of how autonomy was supported-the observation paths-were observed during the observation period. An example of a path is described below:

\section{(A) Initiative: Nurse.}

Nurse Anny picks up clothes from Mr Maas' closet.

(B) Facilitating autonomy: Engaged in choice.

Nurse Anny walks up to Mr Maas and shows the pair of clothes and says, 'do you want to wear these today'?

(C) Resident response: Positive reaction.

Mr Maas looks at the clothes and briefly nods to nurse Anny.

(D) Staff reaction: Not needed to be scored.

Nurse Anny puts down the clothes and helps Mr Maas to take off his pajamas.

After finishing all observations, the research team held several meetings to discuss and interpret the type of observation paths. Insight into the rich variety of possibilities and different approaches helped to support the interpretation process. We used the qualitative data (ie, the field notes) to interpret the quantitative research findings as collected during the observations. This led to a categorization into either "autonomy supporting," "autonomy undermining," "autonomy impeding," or "undefined." Figure 1 lists all possible 21 observation paths and Table 4 provides a description of the interpretation. A detailed overview of the categorization of the observation paths can be found in Supplementary Table 1.

\section{Autonomy supporting}

Autonomy supporting observation paths occurred $60 \%$ of the time. This category can be described as staff-resident interactions that fully support resident autonomy. All observation paths within this category ended positively. In these paths, the resident agreed (either verbal or nonverbal) to the nurse's request, and/or the nurse did not impede the resident's autonomy. The nurse listened to the resident and engaged the resident in choice by being sensitive to the resident's needs and wishes. Examples of situations of supporting of autonomy are:

After Mrs Meyer was washed and had put on clothes, she walks to the bathroom and picks up the comb and started brushing her hair; while nurse Patricia was making up the bed, she watched Mrs Meyer brush her hair, and let her finish the task.

Ready to have breakfast, Mrs Pieters was brought to the breakfast table in her wheelchair; 'Good morning Annie,' nurse Katy says with a smile. Nurse Katy picks up the bread cart and says: 'here you go,' and nurse Katy shows Mrs Pieters pieces of brown and white bread, and Mrs Pieters nods toward the brown bread; nurse Katy picks up a plate and gives Mrs Pieters a slice of brown bread.

\section{Autonomy impeding}

In $25 \%$ of the observations, the interaction between staff and resident impeded resident autonomy. The nurse was not sensitive to resident autonomy, did not try to hear or figure out the resident's needs during the care activity, and refrained from personal contact. The nurse did not identify resident's needs and wishes, and seemed mainly concerned with performing care tasks. In general, we did not observe a personal approach. Residents did not actively respond and appeared to follow whatever the nurse was doing. Examples of manifestations of autonomy impeding are:

After being brought to the breakfast table, Mrs Maas sat down and got a 'good morning.' Nurse Anny pours coffee into a cup and puts it on the table while she looks at the other 6 residents who sit at the table; she gives Mrs Maas a plate and sits down beside another resident to help him.
Nurse Mary picks up clothes from the chair, and gently throws them on the bed and rapidly rolls up the shirt to help Mr Dijk with getting dressed. As Mr Dijk is not able to speak, nurse Mary refrains from verbal interaction and puts no effort into making contact; $M r$ Dijk underwent the care activity.

\section{Autonomy undermining}

In $1 \%$ of the observations, the interaction between staff and resident undermined resident autonomy. The nurses neglected and/or ignored residents' expressed need(s) and wish(es). Examples of situations in which autonomy was undermined are:

After a rushed shower where Mrs Visser got agitated, nurse Monica is in a hurry to do all consecutive care activities. Nurse Monica puts a t-shirt over Mrs Visser's head while answering a colleague's question, who just enters the room. Mrs Visser looks toward the floor, and nurse Monica kept talking with her colleague while finishing the task. Mrs Visser moans and refuses to cooperate; nurse Monica ignores Mrs Visser's reaction and roughly continues the care activity.

After being moved out of bed by a medical lift, Mrs Peters was put on the toilet. Nurse Emmy turns on the shower and says to the observer 'it's just easier showering her as she already sits on the toilet than moving her to the medical shower chair,' and meanwhile starts washing Mrs Peters without any cues, nor did she check for a right temperature. Mrs Peters moans and freezes when the water touches her skin, while nurse Emmy says to the observer: 'Mrs Peters doesn't like showering, but today is showering day,' and continues to shower.

\section{Undefined}

In $14 \%$ of instances, we could not interpret the observation paths. We could not directly define observation paths within this category as facilitating, impeding, or undermining. The support of resident autonomy varied, as we could identify several perspectives on the situation. Examples of situations within this category are:

In an effort to verbally engage Mr Prins in the choice of clothes, nurse John asks, 'Shall we put these trousers on today?' and looks at Mr Prins, but receives no response. Without further effort to get Mr Prins to understand what he was asking, nurse John quickly puts on the trousers. After asking $M$. Prins for a type of $t$-shirt, he again receives no reaction. Nurse John finishes every consecutive care activity.

During breakfast, where residents sit at 2 large tables and there is a lot of background noise, nurse Clara gives Mrs Smit a slice of bread with cheese, looks at her and says, 'There you go, a nice slice of bread' and friendly laughs at her. Mrs Smit would not eat, until-after a while-nurse Clara asks, 'You don't like this?' and Mr. Smit moves her plate. Nurse Clara: 'I'll get you some raisin bread, here you go' and Mrs Smit starts to eat.

Within this category, many missed opportunities are identified, which are not truly facilitating, undermining, or impeding, however, the nurse's approach regarding the care activity could have been more autonomy supporting. The nurse did put an effort into making personal contact, however, most of the cues were verbally orientated and the nurses did not always take enough time to make sure that residents understood what was asked or suggested (either with verbal or nonverbal cues).

Further descriptive analyses showed that autonomy undermining and impeding observation paths were more often seen for residents with low cognitive functioning (ie, in approximately $70 \%$ of cases). Autonomy supporting observation paths were more commonly seen during the care for residents with higher levels of cognitive functioning (ie, in more than $60 \%$ of cases).

\section{Context Across Locations and Nurses}

As observations took place in 9 different nursing home wards, we observed differences regarding working procedures and physical 


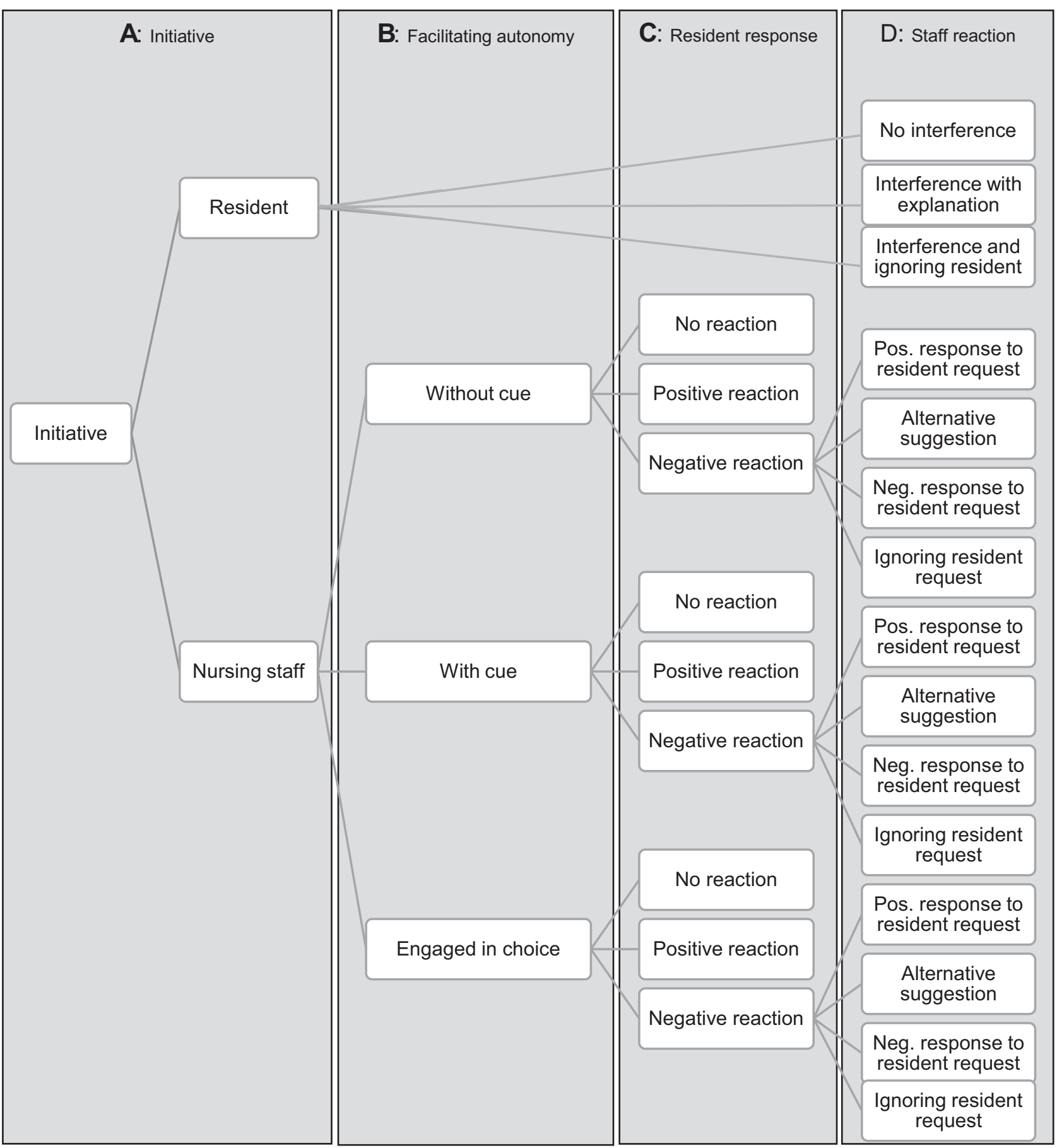

Fig. 1. Representation of observation paths. (A) Initiative; (B) Facilitating autonomy; (C) Resident response; (D) Staff reaction.

environment to support or impede resident autonomy. Regarding working procedures, it seemed that each nurse used a similar approach for all residents. As we observed residents during 3 randomly chosen mornings, we observed the same resident in interactions with different staff members. For example:

Mr Willems was helped by nurse Tony, during 2 observation mornings. Tony did not give any cues nor did he engage M. Willems in choice, and seemed mostly concerned with finishing the care tasks on time. During these 2 mornings, M. Willems showed almost no verbal or nonverbal reaction to the care activities. During the third observation, a different nurse, Laura, helps Mr Willems and approaches Mr Willems with much more patience by taking time, tries to make eye contact with every new action, and frequently tries to involve Mr Willems in choice. Then, Mr Willems frequently laughs when nurse Laura makes eye contact and even tries to speak.

Regarding breakfast, we observed differences across locations. For instance, in some small-scale wards, nurses only served breakfast when all 6 residents had received physical care and were ready to have breakfast together at the table, promoting the "eating with family, just like old times" vision. At other locations, staff members were present at 8 a.m. and served or helped residents when they got into the communal dining room. These staff members were not educated as 
Table 4

Definitions of the Interpretation of Autonomy Manifestations and Their Occurrence

\begin{tabular}{lll}
\hline Interpretations & Definition & $\mathrm{n}(\%)$ \\
\hline $\begin{array}{c}\text { Autonomy } \\
\text { supporting }\end{array}$ & $\begin{array}{c}\text { Resident autonomy was fully supported by the } \\
\text { staff member; residents' expressed needs and } \\
\text { wishes were met }\end{array}$ & $755(60 \%)$ \\
$\begin{array}{c}\text { Autonomy } \\
\text { impeding }\end{array}$ & $\begin{array}{c}\text { Resident autonomy was impeded by the staff } \\
\text { member; residents' needs and wishes were } \\
\text { not taken into account by staff } \\
\text { undenomy }\end{array}$ & $320(25 \%)$ \\
Rndefined & $\begin{array}{l}\text { Resident autonomy was undermined by the } \\
\text { staff member; the expressed needs and } \\
\text { wishes of the resident were ignored } \\
\text { The extent to which resident's autonomy was } \\
\text { supported cannot directly be defined as } \\
\text { facilitating, undermining, or impeding; } \\
\text { variations existed regarding if and how } \\
\text { resident autonomy was supported, as several } \\
\text { perspectives on the care activity and its } \\
\text { interpretation could be identified }\end{array}$ & \\
\hline
\end{tabular}

nurses; however, the manager accepted them based on their strong affinity with caring for residents with dementia. At some locations, breakfast was already set up at the table in order for residents to choose from different types of bread or drinks, whereas others made sandwiches or drinks at the kitchen or cart that was not in the resident's sight.

Some locations had set up surveillance technology, which was most likely installed as a viable alternative to physical restraints. Although using this technology could interfere with resident autonomy, we observed that some nurses used it as a way to increase resident autonomy. For example, sensors that are linked to the nurse's beeper were placed beside the bed. When a resident got up, the nurse would go and check if the resident needed help. In addition, in-bedroom cameras were linked to computer displays to get information on whether or not residents were awake and in need of help.

Furthermore, we observed differences in ambience, often related to the amount of nurses present and their talking behavior. For example, when residents were helped by 2 nurses, personal attention was either increased due to doubled social interactors, or was decreased by nurses chatting together while finishing care activities.

\section{Discussion}

The current study described the extent to which staff supported or impeded the autonomy of nursing home residents with dementia during staff-resident interactions. The results indicate that staff supported resident autonomy during staff-resident interactions in more than one-half of the cases. In addition, data suggest that staff's approach can increase resident autonomy, as resident consent and engagement in care activities appeared greater when staff actively supported resident autonomy. Nonetheless, there were still many cases in which staff seemed to ignore resident's needs and wishes. In addition, differences within staff's approach, working procedures, and physical environment exist, which may support or impede resident autonomy.

This study illustrates that staff use various ways to support resident autonomy, even though residents face difficulties in expressing their autonomy. Previous research confirms that staff support in decision-making for residents in residential care can lead to a greater sense of autonomy ${ }^{19,25}$ Residents can achieve autonomy in the relationship with their social environment, regardless of being reliant on others in addressing their needs and wishes. ${ }^{13}$ The current study indicates that during staff-resident interactions, staff supported resident autonomy in more than one-half of the cases. This was particularly evident when staff offered choice or when staff explained the care activity, and waited for resident's consent to pursue the care activity. This is in accordance with previous work that showed different styles that staff use to either encourage or discourage participation in decision-making for residents with dementia. ${ }^{40}$ These previous results suggest that positive communication and enabling characteristics within communication can enhance resident autonomy. In addition, engaging residents in choice is considered a sign of respect, and enhances the feeling of being seen as a person with needs and wishes. ${ }^{1,41}$

This study indicates that residents were often not actively or fully engaged in the care activity. Staff play a major role in either supporting or impeding autonomy during morning care, as they initiate care in the majority of care activities. However, this study found that staff did not engage the resident one-third of the time in care activities, and consequently, the resident did not actively consent to the care activity. Both residents and staff are at risk of becoming institutionalized, as staff mainly focus on residents' cognitive impairment and lack of decision-making capacity. ${ }^{20,42}$ Staff often base their caregiving approach on care plan documents and perceive this time-saving strategy as autonomy supporting. ${ }^{19}$ This might explain why staff in the current study did not always seek residents' preferences during interactions. This strategy, however, is perceived as contradictory to getting to know the person and exceeds ways to understand the resident with dementia as a person. ${ }^{1}$ This study shows how staff approach residents in supporting autonomy, using a variety of verbal and nonverbal communication. Hence, staff need to recognize and be aware of the importance and capability of residents with dementia to be engaged in meaningful social interaction. ${ }^{43}$ Staff need to be given adequate time to receive educational support that could improve skills to better support autonomy. Consequently, residents might have more positive care experiences and resident distress might reduce. ${ }^{44,45}$

Another finding is that challenges seem to exist in supporting autonomy for residents with severely high cognitive impairment. Results indicate that the chances of being engaged in care were lower for residents with a poor level of cognitive functioning. We observed that staff especially encountered challenges when caring for residents who faced difficulty conveying or knowing what they need or want. Staff may find it difficult to perceive and recognize residents with dementia as relational human beings because of their incapability to express needs and wishes. ${ }^{41}$ Previous research indicates that staff acknowledge the importance of offering choice to residents who face challenges to make decisions. ${ }^{15,45}$ Nonetheless, staff often experience difficulties in supporting autonomy for residents with extremely severe dementia. Staff might not keep up with the increasing complexity of care, do not have sufficient competences to care for residents with severe dementia, or some may not see them as equal human beings with the same needs. ${ }^{41,46}$ Staff need to be given time to prioritize psychosocial needs, such as resident autonomy, as opposed to solely prioritizing physiological and biomedical needs. ${ }^{47,48}$ Therefore, staff might benefit from receiving practical dementia care education, and sufficient resources and time to improve care that supports resident autonomy. ${ }^{49,50}$

The results of this study are subject to certain limitations. For instance, we only observed the support of resident autonomy during morning care which was analyzed using descriptive statistics. Therefore, this study cannot provide information on whether or not this is representative for all daily activities and it may not be generalizable to other groups. In addition, although we asked residents and staff to maintain their usual routine, potential participant bias might have affected the outcome, as participants might have behaved differently knowing that they were being observed. This could have led to more autonomy supporting observations in which residents were better engaged in choice. Unfortunately, because of the methods used, this study did not assess whether or not residents themselves experienced 
more or less support of their autonomy, and how they felt about it. This study does, however, indicate that engaging residents in choice is more autonomy supportive, as more positive reactions were observed when staff asked questions or gave different options. Although this study had its methodological limitations, observations were performed by multiple observers using a standardized observation manual to confirm that each observer conducted and scored the same steps.

\section{Conclusions and Implications}

The findings of this exploratory study show that the autonomy of nursing home residents with dementia is supported in more than onehalf of interactions with staff. Nonetheless, there remains a large part in which autonomy is impeded, indicating that there is a need for further improvement. Therefore, it is important to develop interventions to support staff with education and practical skills in order to optimally support the autonomy of nursing home residents with dementia. Further studies on interventions to educate staff need to be carried out to better support autonomy for residents with dementia living in a nursing home. Our results suggest that cognitive and physical functioning might be related to the level of support. Additional research is needed to confirm this finding and to optimize care that supports resident autonomy for residents with very low levels of cognitive functioning and residents with challenges to expressing themselves verbally. As this study suggests that there are differences in resident approach between individual staff members, peer learning and peer support within nurse teams might improve knowledge and skills by means of experimenting, sharing feedback, and challenging each other's viewpoint and approach. ${ }^{49,50}$ Furthermore, research needs to be carried out to explore if staff background (eg, experience and education) might relate to how they support or interact with residents.

\section{Acknowledgments}

We thank the nursing home residents and the staff of the participating nursing home wards, as we would not have been able to conduct this study without their help and collaboration. We express our appreciation to Niels Hameleers, researcher and data scientist at the Department of Health Services Research, who supported the researchers by giving statistical advice and by sharing statistical analysis software knowledge.

\section{References}

1. Kitwood T. Dementia reconsidered: The person comes first. Philadelphia: Open University Press; 1997.

2. Zimmerman S, Cohen LW. Evidence behind the green house and similar models of nursing home care. Aging Health 2010;6:717-737.

3. Fazio S, Pace D, Flinner J, Kallmyer B. The fundamentals of person-centered care for individuals with dementia. Gerontologist 2018;58:10-19.

4. Brooker D. Person-centred dementia care: Making services better. London: Jessica Kingsley Publishers; 2006.

5. Bern-Klug M. Psychosocial care is basic, improves medical outcomes, and can be taught, but must be better understood. J Am Med Dir Assoc 2000;19: 1033-1034.

6. Ryan RM, Deci EL. Self-determination theory and the facilitation of intrinsic motivation, social development, and well-being. Am Psychol 2000;55:68-78.

7. Simmons SF, Rahman A, Beuscher L, et al. Resident-directed long-term care: Staff provision of choice during morning care. Gerontologist 2011:51:867-875.

8. McCormack B. Autonomy and the relationship between nurses and older people. Ageing Soc 2001;21:417-446.

9. Morgan LA, Brazda M. Transferring control to others: Process and meaning for older adults in assisted living. J Appl Gerontol 2013;32:651-668.

10. Verkerk MA. The care perspective and autonomy. Med Health Care Philos $2001 ; 4: 289-294$

11. Bennett CR, Frankowski AC, Rubinstein RL, et al. Visitors and resident autonomy: Spoken and unspoken rules in assisted living. Gerontologist 2015;57: 252-260.
12. Boyle G. Autonomy in long-term care: A need, a right or a luxury? Disabil Soc 2008;23:299-310

13. Mallidou AA, Cummings GG, Schalm C, Estabrooks CA. Health care aides use of time in a residential long-term care unit: A time and motion study. Int J Nurs Stud 2013;50:1229-1239.

14. Schnelle JF, Bertrand R, Hurd D, et al. Resident choice and the survey process: The need for standardized observation and transparency. Gerontologist 2009; 49:517-524.

15. Simmons SF, Rahman AN. Next steps for achieving person-centered care in nursing homes. J Am Med Dir Assoc 2014;15:615-619.

16. Den Ouden M, Kuk NO, Zwakhalen SMG, et al. The role of nursing staff in the activities of daily living of nursing home residents. Geriatr Nurs 2017;38: 225-230.

17. Christenson AM, Buchanan JA, Houlihan D, Wanzek M. Command use and compliance in staff communication with elderly residents of long-term care facilities. Behav Ther 2011;42:47-58.

18. Davies S, Ellis L, Laker S. Promoting autonomy and independence for olde people within nursing practice: An observational study. J Clin Nurs 2000;9: $127-136$.

19. Fetherstonhaugh D, Tarzia L, Bauer M, et al. The red dress or the blue?: How do staff perceive that they support decision making for people with dementia living in residential aged care facilities? J Appl Gerontol 2016;35: 209-226.

20. Williams KN, Herman RE. Linking resident behavior to dementia care communication: Effects of emotional tone. Behav Ther 2011;42:42-46.

21. Heggestad AK, Nortved P, Slettebo A. Like a prison without bars: Dementia and experiences of dignity. Nurs Ethics 2013:20:881-892.

22. Smebye KL, Kirkevole M, Engedal K. How do persons with dementia participate in decision making related to health and daily care? A multi-case study. BMC Health Serv Res 2012;12:241.

23. Munthe C, Sandman L, Cutas D. Person centred care and shared decision making: Implications for ethics, public health and research. Health Care Ann 2012;20:231-249.

24. Corazzini KN, Anderson RA, Bowers BJ, et al. Toward common data elements for international research in long-term care homes: Advancing person-centered care. J Am Med Dir Assoc 2019;20:598-603.

25. Sherwin S, Winsby M. A relational perspective on autonomy for older adults residing in nursing homes. Health Expect 2010;14:182-190.

26. Vernooij-Dassen M, Moniz-Cook E. Person-centred dementia care: Moving beyond caregiving. Aging Ment Health 2016;20:667-668.

27. Tuinman A, de Greef MHG, Krijnen WP, et al. Examining time use of Dutch nursing staff in long-term institutional care: A time-motion study. J Am Med Dir Assoc 2016;17:148-154.

28. Hoek LJM, van Haastregt JCM, de Vries E, et al. Factors influencing autonomy of nursing home residents with dementia: The perception of family caregivers. J Nurs Home Res 2019;5:33-39.

29. Persson T, Wasterfors D. Such trivial matters: How staff account for restrictions of residents' influence in nursing homes. J Aging Stud 2009;23:1-11.

30. Van Hoof J, Verbeek H, Janssen BM, et al. A three perspective study of the sense of home of nursing home residents: The views of residents, care professionals and relatives. BMC Geriatr 2016;16:169.

31. Wilberforce M, Challis D, Davies L, et al. Person-centredness in the care of older adults: A systematic review of questionnaire-based scales and their measurement properties. BMC Geriatr 2016;16:1-12.

32. Chappell NL, Reid RC, Gish JA. Staff-based measures of individualized care for persons with dementia in long-term care facilities. Dementia (London) 2007;6: 527-547.

33. Edvardsson D, Fetherstonhaugh D, Nay R, Gibson S. Development and initial testing of the Person-centered Care Assessment Tool (P-CAT). Int Psychogeriatr 2010;22:101-108.

34. White DL, Newton-Curtis L, Lyons KS. Development and initial testing of a measure of person-directed care. Gerontologist 2008;48:114-123.

35. Molloy DW, Alemayehu E, Roberts R. Reliability of a standardized Mini-Mental State Examination compared with the traditional mini-mental state examination. Am J Psychiatry 1994;148:102-105.

36. Verbeek H, van Rossum E, Zwakhalen SMG, et al. The effects of small-scale, homelike facilities for older people with dementia on residents, family caregivers and staff: Design of a longitudinal, quasi-experimental study. BMC Geriatr 2009;9:252-264.

37. Folstein MF, Folstein SE, McHugh PR. Mini-Mental State: A practical method for grading the cognitive state of patients for the clinician. J Psychiatr Res 1975;12: 189-198.

38. de Haan R, Limburg M, Schuling J, et al. Klinimetrische evaluatie van de Barthel Index: Een maat voor beperkingen in het dagelijks functioneren. Ned Tijdschr Geneeskd 1993;137:917-921.

39. Fields LM, Calvert JD. Informed consent procedures with cognitively impaired patients: A review of ethics and best practices. Psychiatry Clin Neurosci 2015; 69:462-471.

40. Davey MF, Clarke AM. Communication and decision making among residents with dementia. Geriaction 2004:22:17-24.

41. Heggestad, Nortvedt P, Slettebo A. Dignity and care for people with dementia living in nursing homes. Dementia (London) 2015;14:825-841.

42. Ward R, Vass AA, Aggarwal N, et al. A different story: Exploring patterns of communication in residential dementia care. Ageing Soc 2008;28: 629-651. 
43. Livingston G, Barber J, Marston L, et al. Prevalence of and associations with agitation in residents with dementia living in care homes: MARQUE crosssectional study. BJPsych Open 2017;3:171-178.

44. Shaw C, Williams KN, Perkhounkova Y. Educating nursing home staff in dementia sensitive communication: Impact on antipsychotic medication Use. J Am Med Dir Assoc 2018;19:1129-1132.

45. Lillekroken D, Hauge S, Slettebo A. The meaning of slow nursing in dementia care. Dementia (London) 2017;16:930-947.

46. Slettebo A, Kirkevold M, Andersen B, et al. Clinical prioritizations and contextual constraints in nursing homes-a qualitative study. Scand J Caring Sci 2010;24:533-540.
47. Cameron N, Fetherstonhaugh D, Bauer M, Tarzia L. How do care staff in residential aged care facilities conceptualise their nonverbal interactions with residents with dementia and what relevance has this for how residents' preferences and capacity for decision-making are understood? Dementia (London) 2018; 1471301218798422.

48. Egede-Nissen V, Jakobsen R, Sellevold GS, Sorlie V. Time ethics for persons with dementia in care homes. Nurs Ethics 2013;20:51-60.

49. Edmondson AC, Dillon JR, Roloff KS. Three perspectives on team learning. Acad Manage Ann 2007;1:269-314.

50. Van Woerkom M, Croon M. The relationships between team learning activities and team performance. Personnel Rev 2009;38:560-577. 


\section{Supplementary Material: Detailed Description of How Observation Paths Were Scored}

(A) Initiative for care activity

Who initiated the care activity? This consisted of 3 options: resident, staff member, and other (volunteer, family caregiver, other). If a staff member or other person initiated the care activity, the next step, step B, was scored. If the resident initiated the care activity, step D was immediately scored and steps B and C did not need to be scored.

\section{(B) Facilitating autonomy}

How did the nursing staff member approach the resident during the care activity? Does this approach lead to the support of resident autonomy? The step consisted of 3 options: care activity without a verbal or nonverbal cue; care activity with verbal or nonverbal cues; and care activity with active support of choice. When a care activity was performed without a verbal or nonverbal cue, the resident was not actively engaged in choice in the care activity, and the nurse did not pay attention to resident autonomy. When the care activity with a verbal or nonverbal cue was performed, the nurse prepared the resident for the care activity by providing visual or auditory stimulation that related to the care activity, and paid attention to the resident's understanding of the cue. A care activity with active support of choice was scored if the resident was actively engaged in choice. When this step (step B) is scored, then step C is also scored.

(C) Resident response to staff approach

How did the resident respond to the staff member's approach? This step consists of 3 options: no reaction, positive reaction, and negative reaction. No reaction was scored when the resident did not show any response or just complied with the task given by the staff member, without giving clear permission. A positive reaction was scored in case of a clear sign of permission or positive response of the resident, for example when answering positively, nodding, or blinking the eyes. A negative reaction was scored in the case of resistance of the resident to the staff member's task or approach, either verbally or nonverbally. If the latter option was scored, then step D was also scored. If not, the observation path ends here.

(D) Staff reaction to resident response

How did the staff member react to the resident's response? This step consists of 4 options: staff member complies with the resident's request or reaction; staff member proposes an alternative, and resident agrees; staff member verbally responds to the resident, but decides to do what he/she (staff member) wants; and staff member ignores the resident's reaction. 
Supplementary Table 1

Detailed Overview of the Categorization of the Observation Paths

\begin{tabular}{|c|c|c|c|c|c|}
\hline \multirow[t]{2}{*}{ Categories } & & \multicolumn{4}{|c|}{ Observation Paths $(\mathrm{n}=21)$} \\
\hline & & A & $\mathrm{B}$ & $\mathrm{C}$ & $\mathrm{D}$ \\
\hline \multirow[t]{5}{*}{ Autonomy supporting } & 1 & Resident & - & - & No interference \\
\hline & 2 & Nursing staff & With cue & Positive reaction & - \\
\hline & 3 & Nursing staff & With cue & Negative reaction & Positive response to resident request \\
\hline & 4 & Nursing staff & Engaged in choice & Positive reaction & - \\
\hline & 5 & Nursing staff & Engaged in choice & Negative reaction & Pos. response to resident request \\
\hline \multirow[t]{5}{*}{ Autonomy impeding } & 6 & Nursing staff & Without cue & No reaction & \\
\hline & 7 & Nursing staff & Without cue & Positive reaction & \\
\hline & 8 & Nursing staff & Without cue & Negative reaction & Positive response to resident request \\
\hline & 9 & Nursing staff & Without cue & Negative reaction & Alternative suggestion \\
\hline & 10 & Nursing staff & Without cue & Negative reaction & Neg. response to resident request \\
\hline \multirow[t]{4}{*}{ Autonomy undermining } & 11 & Resident & - & - & Interference and ignoring resident \\
\hline & 12 & Nursing staff & Without a cue & Negative reaction & Ignoring resident request \\
\hline & 13 & Nursing staff & With cue & Negative reaction & Ignoring resident request \\
\hline & 14 & Nursing staff & Engaged in choice & Negative reaction & Ignoring resident request \\
\hline \multirow[t]{7}{*}{ Undefined } & 15 & Resident & - & - & Interference \\
\hline & 16 & Nursing staff & With cue & No reaction & - \\
\hline & 17 & Nursing staff & With cue & Negative reaction & Alternative suggestion \\
\hline & 18 & Nursing staff & With cue & Negative reaction & Neg. response to resident request \\
\hline & 19 & Nursing staff & Engaged in choice & No reaction & - \\
\hline & 20 & Nursing staff & Engaged in choice & Negative reaction & Alternative suggestion \\
\hline & 21 & Nursing staff & Engaged in choice & Negative reaction & Neg. response to resident request \\
\hline
\end{tabular}

